\title{
Antimicrobial Stewardship: Optimizing Antibiotic Use in an Era of Increasing Resistance and Rising Costs
}

James C. Pile, MD, FACP, SFHM

Divisions of Hospital Medicine and Infectious Diseases, MetroHealth Campus of Case Western Reserve University, Cleveland, Ohio.

Disclosure: Dr. Pile has no relevant financial conflicts of interest to report.

KEYWORDS: antimicrobial resistance, antimicrobial stewardship, pharmaco-economics, quality improvement.

Additional Supporting Information may be found in the online version of this article.

Clinicians want to use antimicrobials as effectively as possible, but good intentions frequently fail to translate into adherence to best available evidence. This was recognized as early as 1956, when Earnest Jawetz noted that "[The physician] is under great pressure to prescribe the 'newest,' 'best,' 'broadest' antibiotic preparation, prescribe it for any complaint whatever, quickly, and preferably without worrying too much about specific etiologic diagnosis or proper indication of the drug." 1 That was true in 1956, and is more so in 2010 .

The term that has come to describe the collection of practices intended to optimize antimicrobial therapy is "antimicrobial stewardship." The label is a relatively new one; it appears to have been coined in the mid-1990s, and has slowly crept into the medical lexicon since then. However, many clinicians remain uncertain of exactly what antimicrobial stewardship means or what practices characterize it. The 2007 Infectious Diseases Society of America (IDSA) and Society for Healthcare Epidemiology of America (SHEA) guidelines for developing institutional programs to enhance antimicrobial use define antimicrobial stewardship as "an activity that includes appropriate selection, dosing, route, and duration of antimicrobial therapy," with a primary goal of optimizing clinical outcomes while minimizing unintended consequences of antimicrobial use. ${ }^{2}$

In 2004, IDSA published a document titled Bad Bugs, No Drugs that noted a marked decrease in research and development of new antimicrobials within the pharmaceutical industry, at the same time that the number of antibiotic-resistant bacteria was dramatically increasing, particularly within healthcare settings. ${ }^{3,4}$ Since that time, trends in antimicrobial drug development have not appreciably improved, and governmental agencies have been largely silent or ineffective in addressing the problem. ${ }^{5-8}$ The growth of multidrug-resistant and sometimes pan-resistant pathogens, at a time when newer agents with novel mechanisms of action are not available nor expected for years to come, is particularly troublesome. This scenario highlights the necessity of using currently available agents in a manner that prolongs their effectiveness and reduces further emergence and spread of resistant pathogens-ie, the crucial need for improved antimicrobial stewardship.

Antimicrobial stewardship recognizes that antimicrobials are a unique category of drugs, with potential to affect treatment outcomes in patients for whom the drug was not originally intended. For example, cardiac and oncologic medications can be costly, and may certainly be toxic, but their effects are limited to the patient that directly receives them. In contrast, the effects of antimicrobials prescribed to a patient in the hospital (or outside the hospital, for that matter), can ripple across the hospital system and beyond. This reflects the fact that suboptimal use of antimicrobials may induce or otherwise promote the development of antimicrobial-resistant pathogens, with potential wide-ranging impact. ${ }^{9,10}$ Misuse or overuse of antimicrobials can also promote colonization and overgrowth of potentially toxic pathogens within hospitalized patients, such as Clostridium difficile, that may then be transferred widely within the hospital or other healthcare institutions, particularly when infection control measures are also less than optimal. This unique "societal" feature of antimicrobial drugs highlights the vital importance of antimicrobial stewardship within the hospital setting, especially at a time when few novel agents exist in the developmental pipeline, at least for gram-negative pathogens.

Are hospitalists stakeholders in this? The answer is a resounding "Yes," for several reasons. Hospitalists are the dominant prescribers of antibiotics and other antimicrobials in the United States, almost certainly prescribing more antibiotics in the hospital setting than infectious disease specialists, intensivists, or any other medical specialty or subspecialty. As such, hospitalists play a central role in the optimization of antimicrobial use in the hospital setting, including minimizing negative consequences arising from antimicrobial drug misuse or overuse. In addition, the role hospitalists play in this process is likely to increase in the future. The field of hospital medicine has grown from modest beginnings in the mid-1990s to approximately 30,000 
hospitalists in the United States today. ${ }^{11}$ Based on a sample of Medicare beneficiaries, $6 \%$ of general internists were identified as hospitalists in 1995 versus 19\% in 2006, and the percentage of claims for inpatient services provided by general internists who were hospitalists increased from $9 \%$ to $37 \% .^{12}$ Current estimates are that $>50 \%$ of medical inpatients in the United States are cared for by hospitalists (personal communication, J. Miller, Society of Hospital Medicine). Importantly, hospitalists manage patients not only on regular medical floors, but also in intensive care units (ICUs), where antimicrobial resistance is a particular problem. ${ }^{13,14}$ Finally, hospitalists serve as gatekeepers for patients leaving the hospital on either oral or intravenous antibiotics or other antimicrobials. As such, via interactions with primary care physicians, hospitalists can play a key role in improving antimicrobial stewardship not only within, but also beyond, the hospital setting.

Hospital medicine is the first medical specialty to make patient safety and quality improvement central principles of its practice, and antimicrobial stewardship is an under-recognized but central tenet of patient safety. As a consequence, hospitalists are natural allies of stewardship programs. Indeed, antimicrobial stewardship may be considered an example of the "Holy Grail" of quality improvement; ie, an intervention that improves outcomes while leading to cost savings, and should thus resonate with all hospitalists.

A number of clinical practice guidelines or campaigns have been developed by professional societies and governmental organizations in the United States ${ }^{2,15-26}$ and other countries $^{27-30}$ for the promotion of improved antimicrobial stewardship and/or infection control in hospitals and longterm care facilities. The goals of these initiatives, campaigns, or guidelines are to provide information that can be utilized to prevent or slow the development and spread of hospitalacquired infections, particularly those involving antimicrobial-resistant pathogens. In addition, the United States Congress is currently considering the STAAR (Strategies to Address Antimicrobial Resistance) Act to encourage the use of innovative governmental and private approaches to combat this critical and expanding problem. ${ }^{31}$

This supplement to the Journal of Hospital Medicine contains several articles of interest to hospitalists seeking to positively impact patient care through improvements in antimicrobial stewardship. The first article by Christopher Ohl, MD, examines general principles of antimicrobial stewardship programs as they apply to inpatient facilities. The second article by Thomas Lodise, PharmD, explores the effective use of pharmacokinetic-pharmacodynamic principles in antimicrobial stewardship. In the third article, Steven Gordon, MD, moves beyond the hospital setting to discuss antimicrobial stewardship at the time of hospital discharge and beyond. Finally, Arjun Srinivasan, MD, outlines several practical ways in which hospitalists may take leadership roles in stewardship efforts at their institutions. Our hope is that the supplement will be thought-provoking, and ulti- mately lead to greater partnership between hospitalists and other stakeholders in antimicrobial stewardship.

\section{Address for correspondence and reprint requests:}

James C. Pile, MD, MetroHealth Medical Center, Bellgreve 543, 2500

MetroHealth Dr, Cleveland, OH 44109; Telephone: 216-778-5162;

Fax: 413-794-1767; E-mail: james.pile@case.edu Received 11 August

2010; revision received 7 September 2010; accepted 9 September

2010 .

\section{References}

1. Jawetz E. Antimicrobial chemotherapy. Annu Rev Microbiol. 1956;10: 85-114.

2. Dellit TH, Owens RC, McGowan JE Jr, et al. Infectious Diseases Society of America and the Society for Healthcare Epidemiology of America guidelines for developing an institutional program to enhance antimicrobial stewardship. Clin Infect Dis. 2007;44:159-177.

3. Bad bugs, no drugs: as antibiotic R\&D stagnates, a public health crisis brews. Alexandria, VA: Infectious Diseases Society of America; 2004.

4. Spellberg B, Powers JH, Brass EP, Miller LG, Edwards JE Jr,. Trends in antimicrobial drug development: implications for the future. Clin Infect Dis. 2004;38:1279-1286.

5. Boucher HW, Talbot GH, Bradley JS, et al. Bad bugs, no drugs: no ESKAPE! An update from the Infectious Diseases Society of America. Clin Infect Dis. 2009;48:1-12.

6. Rice LB. Federal funding for the study of antimicrobial resistance in nosocomial pathogens: no ESKAPE. J Infect Dis. 2008;197:1079-1081.

7. Spellberg B, Guidos R, Gilbert D, et al. The epidemic of antibiotic-resistant infections: a call to action for the medical community from the Infectious Diseases Society of America. Clin Infect Dis. 2008;46:155-164.

8. Talbot GH, Bradley J, Edwards JE Jr., Gilbert D, Scheld M, Bartlett JG. Bad bugs need drugs: an update on the development pipeline from the Antimicrobial Availability Task Force of the Infectious Diseases Society of America. Clin Infect Dis. 2006;42:657-668.

9. Paterson DL. "Collateral damage" from cephalosporin or quinolone antibiotic therapy. Clin Infect Dis. 2004;38(Suppl 4):S341-345.

10. Weber DJ. Collateral damage and what the future might hold. The need to balance prudent antibiotic utilization and stewardship with effective patient management. Int J Infect Dis. 2006;10:S17-S24.

11. Heisler M. Hospitalists and intensivists: partners in caring for the critically ill--the time has come. J Hosp Med. 2010;5:1-3.

12. Kuo YF, Sharma G, Freeman JL, Goodwin JS. Growth in the care of older patients by hospitalists in the United States. N Engl J Med. 2009;360: 1102-1112.

13. Carlet J, Ben Ali A, Chalfine A. Epidemiology and control of antibiotic resistance in the intensive care unit. Curr Opin Infect Dis. 2004;17:309-316.

14. Kollef MH. Bench-to-bedside review: antimicrobial utilization strategies aimed at preventing the emergence of bacterial resistance in the intensive care unit. Crit Care. 2005;9:459-464.

15. Centers for Disease Control and Prevention. Get smart: know when antibiotics work. Available at http://www.cdc.gov/getsmart/. Accessed June $20,2010$.

16. The Society for Healthcare Epidemiology of America. Compendium of strategies to prevent healthcare-associated infections in acute care hospitals. Available at http://www.shea-online.org/about/compendium.cfm. Accessed June 20, 2010.

17. Rybak M, Lomaestro B, Rotschafer JC, et al. Therapeutic monitoring of vancomycin in adult patients: a consensus review of the American Society of Health-System Pharmacists, the Infectious Diseases Society of America, and the Society of Infectious Diseases Pharmacists. Am J Health Syst Pharm. 2009;66:82-98.

18. Centers for Disease Control and Prevention. Department of Health and Human Services. Infection control in healthcare settings. Available at http://www.cdc.gov/nidod/dhqp/. Accessed February 17, 2010. 
19. Centers for Disease Control and Prevention. Healthcare Infection Control Practices Advisory Committee (HICPAC). Available at http://www.cdc. gov/hicpac/. Accessed February 18, 2010.

20. Centers for Disease Control and Prevention. Campaign to prevent antimicrobial resistance in healthcare settings. Available at http://www.cdc. gov/drugresistance/healthcare/default.htm. Accessed February 18, 2010.

21. Boyce JM, Pittet D. Guideline for Hand Hygiene in Health-Care Settings: recommendations of the Healthcare Infection Control Practices Advisory Committee and the HICPAC/SHEA/APIC/IDSA Hand Hygiene Task Force. Infect Control Hosp Epidemiol. 2002;23:S3-40.

22. Cohen SH, Gerding DN, Johnson S, et al. Clinical practice guidelines for Clostridium difficile infection in adults: 2010 update by the society for healthcare epidemiology of America (SHEA) and the infectious diseases society of America (IDSA). Infect Control Hosp Epidemiol. 2010;31:431-455.

23. Muto CA, Jernigan JA, Ostrowsky BE, et al. SHEA guideline for preventing nosocomial transmission of multidrug-resistant strains of Staphylococcus aureus and enterococcus. Infect Control Hosp Epidemiol. 2003;24: 362-386.

24. Shlaes DM, Gerding DN, John JF Jr., et al. Society for Healthcare Epidemiology of America and Infectious Diseases Society of America Joint Committee on the Prevention of Antimicrobial Resistance: guidelines for the prevention of antimicrobial resistance in hospitals. Clin Infect Dis. 1997;25:584-599.
25. Smith PW, Bennett G, Bradley S, et al. SHEA/APIC guideline: infection prevention and control in the long-term care facility, July 2008. Infect Control Hosp Epidemiol. 2008;29:785-814.

26. Yokoe DS, Mermel LA, Anderson DJ, et al. A compendium of strategies to prevent healthcare-associated infections in acute care hospitals. Infect Control Hosp Epidemiol. 2008;29 Suppl 1:S12-21.

27. Australian Commission on Safety and Quality in Health Care ( 2009). Windows into Safety and Quality in Health Care 2009, ASCQHC, Sydney, Australia. Available at http://www.safetyandquality.gov/au. Accessed June 20, 2010.

28. Allerberger F, Gareis R, Jindrak V, Struelens MJ. Antibiotic stewardship implementation in the EU: the way forward. Expert Rev Anti Infect Ther. 2009;7:1175-1183.

29. Allerberger F, Lechner A, Wechsler-Fordos A, Gareis R. Optimization of antibiotic use in hospitals-antimicrobial stewardship and the EU project ABS international. Chemotherapy. 2008;54:260-267.

30. Earnshaw S, Monnet DL, Duncan B, O’Toole J, Ekdahl K, Goossens H. European Antibiotic Awareness Day, 2008-The first European-wide public information campaign on prudent antibiotic use: methods and survey of participating countries. Euro Surveill. 2009;14:19280.

31. The Infectious Diseases Society of America. Strategies to Address Antimicrobial Resistance (STAAR) Act. Available at http://www.idsociety.org/ STAARAct.htm. Accessed June 20, 2010. 